\title{
Research on Existing Financial Predicament Problems of China's Small-Medium Business Enterprises and Its Countermeasures
}

\author{
Haiyong Ma \\ School of Economics and Management, Changchun University of Science and Technology \\ Changchun 130022, China \\ E-mail: mhymark@gmail.com
}

Received: October 25, $2010 \quad$ Accepted: November 12, $2010 \quad$ DOI: 10.5430/ijba.v1n1p64

\begin{abstract}
Currently, SMEs' financing difficulties have become a major problem threatening the Chinese economy, especially for the Small-Medium business enterprises (SMBEs).This article laid out current situation of SMBEs' Financial Predicament and analysis the factors influencing the SMBEs' financial Predicament. At the end of this article, the authors summarized the countermeasures to the SMBEs' financial Predicament according the actual situation of China.
\end{abstract}

Keywords: Financial Predicament, Business enterprises, Small and medium enterprises

Small-Medium business enterprises(hereinafter referred to as SMBEs) refers to the SME which engaged in such industry that including wholesale and retail trade, accommodation and catering, leasing and commercial service, community service and other services, slaughter, warehouse and logistics operation service(Interim Procedures for the administration special fund for SMBEs development ).

As China's economy continues to thrive, the position of commerce and trade circulation industry in China's economy become more and more outstanding. Consumers demand ranking first in the traditionally three drivers of driving China's economic growth. In recent years, the total volume of retail sales of the social consumer goods gains double-digit growth. In the government work reports for 2010, expand consumption, especially individual consumption was positioned in the first part, Consumption played a much bigger role in fueling economic growth. The report also set out to further expand domestic demand, consolidating, expanding traditional consumption, breeding the dweller's new consumption heat actively, expand Consumer credit, rectifying and standardizing the market order, continue apply and improve various policies which encourage consumption, and all these measures will promote the growth of China's commerce and trade circulation industry.

According to statistics, the present number of SME has exceeded 100 million, accounting for 99 percent of the total number of enterprises in China, of which $70 \%$ are commercial \& trading enterprises, produce end product and service product accounting for $60 \%$ of GDP, the payment of the tax revenue accounting for $50 \%$ of total tax revenues, create $70 \%$ jobs positions in urban areas. SMBEs have already become the main force that promotes growth of Chinese national economy.

Financial predicament may be a prevalent problem for business enterprises, especially for SMBEs. According to preliminary statistics, $11.11 \%$ shows they were flush with funds, $51.85 \%$ shows the basic needs of working capital were meet,33.33\% shows there were obvious financing gap, 3.7\% reflects a serious shortage of funds and the enterprises' normal operation have been affected.

\section{Current situation of SMBEs' Financial Predicament}

1.1 Strong financing demand of enterprises, funding gap were prevalent

The problem of the funds is always the "bottleneck" plaguing each SMBEs, and it is also a worldwide difficult problem. According to a survey to the global retail business made by IBM in 2010, the most outstanding issues that exist in SMBE at present are operations management and the fund problem. Simultaneously, there are signs that in different areas, serious shortage of circulating fund had exerted remarkable influence on the development of SMBE.

Based on the sample questionnaire survey to the SMBEs in Guangdong province in the end of 2009, 33\% of the enterprises surveyed believe that insufficient fund is one of the major reasons which restrict the development of enterprises. $74 \%$ of the enterprises surveyed saw themselves urgent need for financing, but only $30 \%$ of them be successful financing. 


\subsection{Single financing structure and narrow financing channels}

For the irrational financing structure of SMBEs, The enterprises had to rely on themselves and depend more on internal financing. This Single financing structure cannot satisfy the funding requirements of the enterprises, and restricted its overall development.

By now, SMBEs' financing channel includes not only bank loans, equity investments, bond issuance and the introduction of strategic investors. But in actual operation, it didn't leave SMBEs much option. The majority of enterprises take bank loans as the main form or the only form for its source of financing. There are few enterprises to think of using other financial channels, such as financial leasing, Microfinance or small shares transfer. Currently one of the most recognizable collateral for loan maybe these fixed assets such as buildings, equipment, machineries, these assets are characterized for their clear property rights. But for the capital structure of these business enterprises, the proportion of fixed assets to the total asset is not big, and lack of these illiquid assets to met the conditions on mortgages.

\subsection{High financing costs and financing difficulties}

This problem of high financing costs prevails in the area of SMBEs. Take the bank loan for example, the financing costs are mainly consist of these factors as follows: first, the benchmark interest rates and floating interest rates; second, fees of gathering deposits, usually it will be $1 \%-3 \%$ of the total values of bank loan; third, Discount charges; fourth, fees of intermediary business such as commission fees; fifth, collateral assessment costs and mortgage register expenses; and sixth, interest of short term financing. A combination of these factors, the reasonable payment of financing cost is about between $8 \%$ to $11 \%$, and maybe more.

This directly increased financial expenditures and operation costs.

\section{Analysis of SMBEs' financial Predicament}

\subsection{Reasons of bank and financial institutions}

At present, however, there is excess liquidity in the bank; the intensity of the support for the loan to business enterprises is insufficient. All the commercial banks focusing on large enterprises when they granting loans. Compared with its peer competitors, The financing style of Small-Medium commercial \& trading enterprises have these characteristic such as small number of single-loans, high management costs and low profitability. This makes bank paid less attention to the loan to business enterprises, and have no strong passion to exploit new client of business enterprises.

Furthermore, the procedures of bank loans are cumbersome and time-consumed, the implicit costs for the enterprises were too high to get bank loan. Usually it will take months to get a loan from a bank. And some small and medium business enterprises would use civil loan sharking rather than bank loans.

\subsection{Internal reasons from enterprises}

Non-standard management mechanism, low level of management are common in the SMBEs, this make bank difficult to fully grasp these enterprises' true financial status, and influence decision-making process to offer loan, all these factors make it unattractive for commercial bank granting loans to these SMBEs.

Non-standard financial reports, scarce of credibility. The SMBEs' idea of credit is deficiency, with a low level of credit ratings, tax fraud and tax evasion reduced these enterprises' social creditability magnificently.

The incumbent principal of the enterprise has insufficient awareness of financing patterns diversity; most of the enterprises deems the bank loans as the only means to get the source for the enterprises. Too few enterprises will consider using other financing channels.

\subsection{The reasons come from government policy}

In recent years, through industry tax and credit, related department strengthen the power of policy support, improve the business environment. But these policies are mainly focus on the whole small and medium enterprise, in the actual operation, they didn't give special arrangement to the business enterprises, and the SMBEs face more difficulties than small and medium industrial enterprise.

According to a survey report posted by the Commerce Department of Jiangsu province in 2010, by now SMBEs in China face a daunting array of problems: there is no preferential interest rate policies for commercial loans, the financing costs of commercial and trading industries are much higher than other industries. There is no special project-financing loan for maintenance and updating commercial and trading industries, the policy barriers of not permitting the commercial and trading industries take inter-enterprise loan funds have not been cancelled, some SMBEs have to resort to private "financial organization", financing through a much higher interest rate more than $10 \%-40 \%$ of the normal interest rate. All explains the financing policies of SMBEs are in urgent need for adjustment. 


\section{Countermeasures to the SMBEs' financial Predicament}

\subsection{In terms of the banks and other financial institutions}

To solve the question of financial Predicament, by and large, one should begin from the commercial bank. On the on hand ,accelerate the reform of the banking system, on the other hand, loosing financial regulation on a modest scale, break the monopoly state in the financial business, given the small and medium financial enterprises fully development space. What the government should do are open its financial market properly and introduce reasonable and effective financial regulatory standards and improve oversight mechanisms, let the market solve the questions of SMBEs' financial Predicament.

First, commercial banks should serve the SMBEs actively, Understanding the business actively and develops business scope positively. It will be more valuable for the bank to help the SMBEs tide over their difficulties on hard times, to establish a good cooperative relationship with high quality enterprise, instead of putting the icing on the cake. Now some shareholding commercial banks begin to launch new loans species aim at SMBEs and these financial service centers on SME owners, satisfied these entrepreneurs' short-term, small, much-needed funds, and provide other services such as settlement of payment, financial planning, etc. Second, the commercial bank should exploit new financial product which are suitable for the SMBEs. Third, commercial banks should improve the service quality, the feature of SMBEs' financing activity are: financing demand is urgent, short-time of usage and high-frequency of usage. The bank should try their best to simplify the procedures, reducing the loan approval time.

\subsection{In terms of the SMBEs themselves}

First, SMBEs should be attention to shape and maintain their own image, strengthening the idea of credit. The credit of SMBEs include not only its debt paying ability, but its product quality, brand, management ideas of its market prospect, marketing tactics, etc. They should have the credit consciousness, quality consciousness and competition consciousness.

Second, SMBEs should strengthen their financial system construction; increase the transparency of their financial information. They should standardized working of financial management; establish the mechanism to reflect the state of operation and financial condition properly. If conditions permit, SMBEs must publish real accounting statements to society periodically; give the commercial bank and other financial institutions enough confidence in the SMBEs' prospect and business environment.

Third, SMBEs should adopt a multi-channel financial strategy, for example, the cluster financing system is one of the effective ways to solve the problem, currently. There three kinds of cluster financing model relatively mature: secured financing of "Business Circle", supply chain financing and pawn financing of shop franchise.

\subsection{In terms of the roles of government}

The government has effects of booster on the development of SMBEs; the roles of the formulation of laws and regulations, policy guidance, construction of service support system and safeguard measure, all these factors involve the future trend of SMBEs and the construction and perfection of the distribution systems for urban and rural areas as a whole.

First, the government should speeding up the formulation of policies and procedures on the development of SMBEs. On the one hand, it should make the effective policy to solve the problems of number of the SMBEs increases excessively(merger and acquisition), on the other hand, with the implementation of SME Promotion Law, the SME subject legal system will be perfected, it offers legal supports and directions for the financing of SME in many ways.

Also, the government should study and formulate financial policies focused on the SMBEs, expand financing channels. Encourage the establishment of a loan risk compensation fund for SMBEs, improve the financing guarantee system for business and trading enterprises, building a platform of cooperation between banks and enterprises.

Finally, the government should provide excellent management service from the areas of funding, information and intelligence, programs of personnel training, help to resolve dispute between these commercial and trading enterprises. 


\section{References}

Department of market supervision of Ministry of Commerce of People's Republic of China. Survey report (2009).Financing conditions of commercial and trading enterprises in Guangdong province. [Online] Available: http://sczxs.mofcom.gov.cn/aarticle/shangwupl/200912/20091206660632.html

Li, Y. (2010).Cluster financing will help to resolve the Financial Predicament problem. Economic Daily

Liu, Y., and Zhang, M. (2010).Problems and countermeasures of SME's problem of difficulty in financing. China Economic \& Trade Herald

$\mathrm{Xu}, \mathrm{C}$., and Liu, X. (2010).It is not difficult for the commercial and trading enterprises to raise funds. International Business Daily

Zhang, G. (2009).Research on the Solutions of the Difficult Financing Situation of SMEs in China. Doctoral dissertation, Liaoning University. (Chapter 2)

Zhang, Q. (2010).The Analysis on the Financing Advantage and Obstacle of the Small and Medium-sized Enterprise Groups. Technoeconomics \& Management Research, 16, 2-4. 